\title{
2-D Flexural Analysis of the Ulleung Back-Arc Basin, East Sea (Sea of Japan)
}

\author{
Sang-Mook Lee ${ }^{1, *}$, Jong-Won Kim ${ }^{1,2}$, and Chang-Eob Baag ${ }^{2}$ \\ (Manuscript received 11 August 2003, in final form 30 September 2003)
}

\begin{abstract}
The flexural property of the Ulleung back-arc basin was examined along three deep seismic profiles that transect the basin margin. Our method assumes that the crust is stretched according to Airy's isostasy during basin formation, and therefore it has no mechanical strength during the rifting stage. However, upon completion of rifting and cooling, the extended crust gains a finite strength and response to sediment loading in elastic manner. For a given elastic thickness of the crust, we construct a simple 2$D$ model and search for the elastic thickness that best matches the observed gravity anomalies. Of the three profiles, two gave a reasonable fit with the best matching elastic thickness of about $8-10 \mathrm{~km}$. This value is substantially lower than major passive margins, but comparable to young marginal basins that have undergone rapid extension and is largely consistent with the model of Ulleung Basin development. The cause of large gravity anomaly misfit along the third profile across the southwest corner of the Ulleung Basin is unclear. However, our preferred explanation is that a mechanism other than extension and subsidence, such as thrusting and strike-slip faulting related with the late-stage closure of the Ulleung Basin, may be responsible for the crustal structure there.
\end{abstract}

(Key words: Back-arc basin, Elastic thickness, Flexure, Subsidence, Gravity modeling)

\section{INTRODUCTION}

The East Sea (Sea of Japan) is a back-arc basin which lies on the northeastern margin of the Eurasian continent (Fig. 1). Like many young marginal basins that developed at the back-

\footnotetext{
${ }^{1}$ Marine Geo-Resources Division, Korea Ocean Research and Development Institute, Seoul, Korea

${ }^{2}$ School of Earth and Environmental Sciences, Seoul National University, Seoul, Korea

${ }^{*}$ Corresponding author address: Dr. Sang-Mook Lee, Marine Geo-Resources Division, Korea Ocean Research and Development Institute, P.O. Box 29, Seoul 425-600, Korea; E-mail: smlee@kordi.re.kr
} 
arc side of oceanic arc in the western Pacific, it too exhibits a complicated seafloor topography and crustal structure. In particular, a significant physiographical difference exists between the north and south. The northern part is generally characterized by simple morphology with a wide, deep basin underlain by oceanic crust (Japan Basin). This contrasts with the southern section where the topography is much more complicated and numerous rises, continental remnants and plateaus intervene the basins. The Ulleung Basin is located at the southwestern part of the East Sea and is thought to represent a rifting-dominated end-member among a range of extensional basins that have developed in the back-arc setting (Fig. 1).

Although numerous studies have been performed in the last two decades (Chough et al. 2000 and references therein), the formation of the Ulleung Basin remains controversial. Much of the recent debate has focused on the nature of the crystalline basement overlying the sedimentary sequence. The traditional thought is that the basement of the Ulleung Basin is comprised of extended continental crust which was probably modified by volcanic and magmatic activity during and af ter the basin formation (Jolivet and Tamaki 1992). However, this idea was challenged by Kim et al. $(1994,1998)$, who interpreted the crustal velocity structure of the Ulleung Basin as that of an abnormally $(10 \mathrm{~km})$ thick oceanic crust. Lee et al. (1999) agree on the presence of oceanic crust, but insist that the basin may not have developed to a full-fledge production of oceanic crust.

Despite these recent arguments, there are a number of reasons to believe that Ulleung Basin is extended continental crust, which may be affected by volcanism and magmatism during rifting. For example, unlike the Japan Basin to the north, the Ulleung Basin does not show a systematic magnetic anomaly pattern that would indicate seafloor spreading. Also, the basement is far too deep ( $8-9 \mathrm{~km}$ below the sea level) to be oceanic crust, and the basin is surrounded by rifted continental remnants and fragments. Furthermore, the determination of crustal structure based on seismic velocity profile alone can be misleading because the seismic velocity can be quite variable within a single lithological unit and can be ambiguous with different lithologic units sometimes having similar velocities. For instance, recent studies show that seismic velocity of the uppermost crust is largely controlled by factors, such as faulted cracks, fissuring, and subsequent sealing during hydrothermal alterations (e.g., Alt et al. 1996), and therefore some of the velocity changes, which were thought as lithological boundaries, may in fact be alteration boundaries.

According to the evolutionary tectonic model by Yoon and Chough (1995), the Ulleung Basin started from pull-apart opening which lasted from 23-18 Ma (Figs. 2a, b). It then went through differential rotation in middle Miocene (18-12 Ma) (Fig. 2c), followed by back-arc closure (Fig. 2d). An important element of this model is that extension occurred predominantly in the N-S direction, with the eastern Korean continental margin being the locus of major strike-slip movements. With the rotation of Ulleung Basin in middle Miocene, however, it is possible that the eastern continental margin of Korea was also subjected to some extensional stress. The evolutionary difference between the western and southern margins of the Ulleung Basin is reflected in the regional bathymetry (Fig. 1). The southern margin is characterized by a gentle continental slope. This contrasts with the western margin, which has a steep slope, denoted as basement escarpment in Fig. 2. In terms of gravity anomaly, both margins show low values on the slope and at the base of margin, which is interpreted as the 


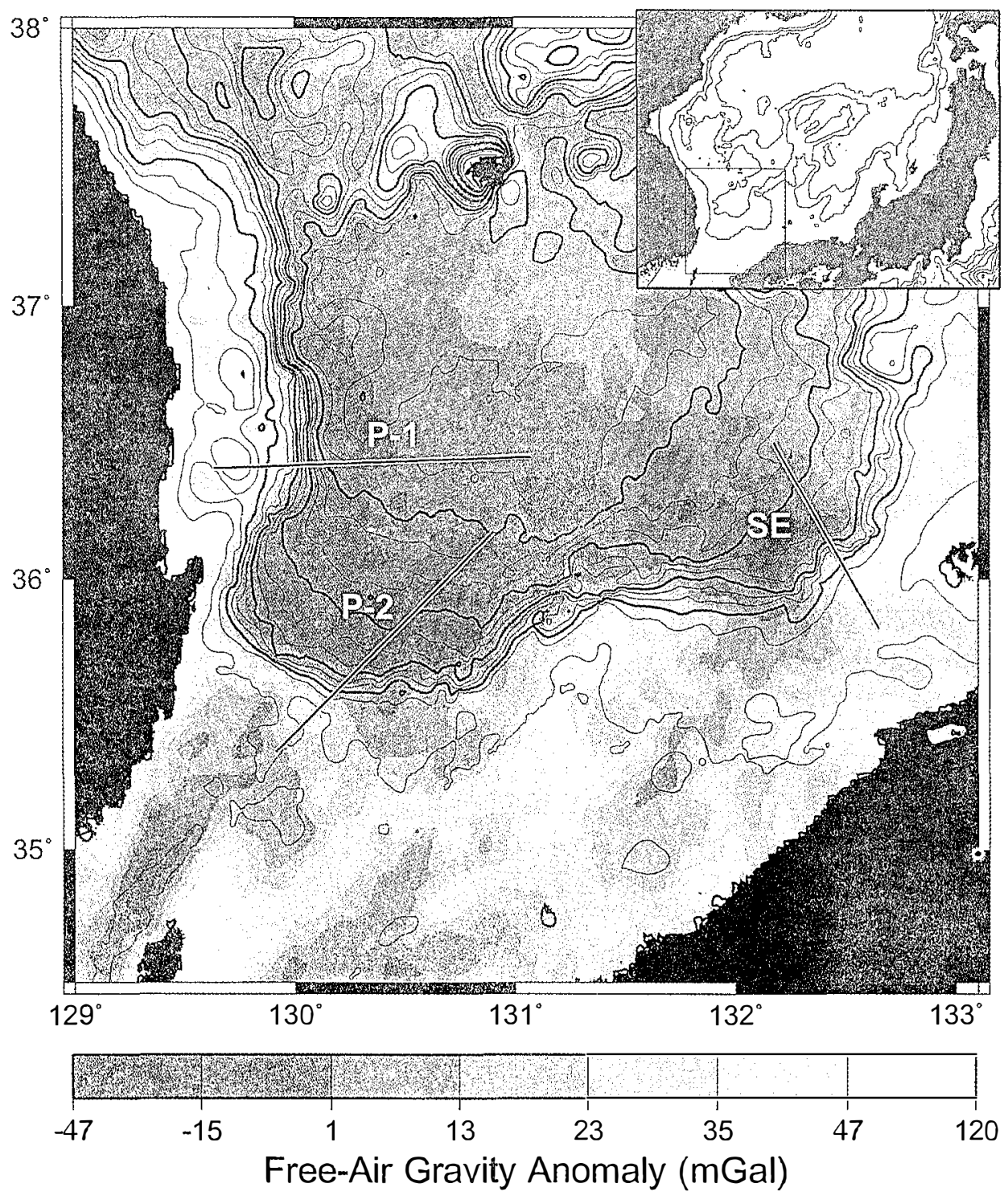

Fig. 1. Map of the East Sea showing the location of the Ulleung Basin (inset). Shaded map showing the satellite-derived free-air gravity anomaly in the Ulleung Basin. Superimposed are bathymetric contours at $150 \mathrm{~m}$ intervals. Three deep seismic profiles (SE, P-1 and P-2) used in this study for flexural modeling are shown in solid lines. Notice the low gravity anomaly along the rim of the basin and the difference in the slope gradient between the south and western margins of the Ulleung Basin. Also an area just slightly north of the Tsushima Island has a distinct low gravity anomaly. 
presence of relatively thick sediment at those locations (Fig. 1).

A new insight into the long-term mechanical properties and the overall structure of the Ulleung Basin crust may be gained by investigating the response of the basin to sediment loading using a simple mechanical model. Flexural analysis has been widely used in the last two decades to understand the extensional tectonics and rifting of various types of basins (for extensive review see Watts 2001), but has never been performed for the Ulleung Basin. Only the subsidence analysis of the Ulleung Basin was performed by Chough and Barg (1987) using marine stratigraphy data collected from a number of wells and assuming Airy's isostasy at a single point for backstripping. In this study, we use 2-D modeling and take the flexural isostasy into account. Also, more realistic assumptions on the behavior of the basin due to extension are employed than in previous work. While simple 2-D modeling may leave out many detailed aspects of margin structure, the results of this study may serve as an important guideline for more elaborate analyses.

\section{DATA}

We used three recent seismic profiles collected in the W, S, and SE parts of the Ulleung Basin during recent wide-angle refraction experiments using ocean-bottom seismometers and airguns (Fig. 1). Profile SE was obtained in 2000 during a collaborative survey by Japanese scientists onboard R/V Tansei-maru at the SE corner (Sato 2002). Profiles P-1 and P-2 were collected in 1998 jointly by Korea Ocean Research and Development Institute (KORDI), Chiba University of Japan and Pacific Oceanological Institute of Russia onboard R/V Gagarinsky (Kim et al. 2003; Sato 2002).

In this study, we used the sedimentary layer thickness values as determined by Sato (2002), based on P-wave velocity profiles from ocean-bottom seismometers. In the cases of P-1 and $\mathrm{SE}$ profiles, additional information from multichannel seismic reflection data was used to derive the upper crustal structure. The sediment/crust interface can be clearly identified from most of the profiles. In some places along P-2 profile, however, the crustal basement can not be defined with certainty due to usually thick sediment. In general, sediment is thin near the margin but becomes thick toward the basin.

A number of different gravity data sets exist in our study area. We used the free-air gravity anomaly data set derived from satellite altimetry by Sandwell and Smith (1997). While this data set has a lower resolution and is perhaps less precise than shipboard measurements, it covers all three areas and does not require any additional correction for comparison. Our preliminary analysis shows that the overall trend of the shipboard measurements is similar to the free-air gravity anomaly derived from the satellite. It is important to note that because we are interested in explaining the overall trend of gravity anomaly, minor differences between different sets of gravity data and short-wavelength anomalies $(<20-30 \mathrm{~km})$ are not so important.

\section{METHOD}

The basic concept of the method used in this study is outlined by Watts $(1988,2001)$. It 
assumes that the crust is isostatically compensated during crustal extension, which is equivalent to stating that it has no mechanical strength during rifting stage (Figs. 3a, b). But, once the rifting has ended, the basin crust acquires mechanical strength and the basin deforms elastically to the overloading sediments. Figs. 3c, d illustrate two different cases where the crust has a low and high mechanical strength, respectively, along with the difference in gravity anomalies.

The argument that crust is isostatically compensated during basin formation is not unreasonable for back-arc basins, such as Ulleung Basin, if one considers that during rifting the basin crust is heated, as rapid crustal thinning causes the mantle to upwell. This in turn triggers the decompressional melting (McKenzie 1978) and emplacement of new material in the extended crust. However, according to the analysis of seismic sections interpreted by Lee et al. (1999), there appears to be only one or two places within the Ulleung Basin where a substantial amount of material has been added to the crust. Therefore, most of the extensional stress is probably accommodated by the stretching of the lower crust. Experimental studies (e. g., Goetze 1978) and numerous observations in various geological settings (e.g., Watts 2001) have shown that lower crust exhibits a ductile behavior during extension. The onset depth of ductility depends most likely on the strain rate and thermal history; for example, a lower strain rate and higher temperature will give rise to a greater region of ductile deformation. Once the basin has formed, a conductive cooling takes place and over time the basin will become cold again, and thus the crust will gain mechanical strength. The amount that basin crust deforms under loading will depend on the flexural rigidity and thus on the elastic thickness $\left(T_{e}\right)$, and the difference in deflection will be reflected in the gravity anomaly (Figs. 3c, d).

An important assumption in our method is that elastic thickness of the basin is uniform and that the deflection in the elastic crust results in the same amount of deflection at the mantle/ crust interface. This assumption is not unreasonable because, although it is quite variable and depends on the crustal age, the elastic thickness is generally $25-50 \%$ of the seismic thickness (Watts 2001). Also according to Karner et al. (1983), like the oceanic crust, the elastic thickness of continental crust generally follows the depth to the $450^{\circ} \mathrm{C}$ isotherm. The assumption that elastic thickness is uniform may not necessarily be true on the margin side (Figs. 3c, d) as the elastic thickness there may be substantially higher. Some tests were made to check how thicker elastic thickness on the margin affects the gravity anomaly. Our test results show that the elastic thickness on the margin side does affect the gravity modeling results significantly. This is because in our model, in order to prevent the model from making downward rigid body motion upon sediment loading, the left side of the model is already fixed, and having a relatively rigid continental margin also prevents the region from deforming under sediment loading.

It is worthwhile to note that thermal subsidence is not treated separately in our model. Instead, it is incorporated in the total tectonic subsidence together with the tectonic subsidence resulting from crustal extension. The major benefit of not considering the thermal subsidence separately is that the modeling can be greatly simplified, as one does not have to take into account another set of parameters related with timing of various events. Of course, the disadvantage is that it may result in some errors in our flexure estimation, depending on the stretching factor. However, according to our preliminary analysis using the instantaneous rifting model of McKenzie (1978), the thermal subsidence is a few hundred meters at most and is 

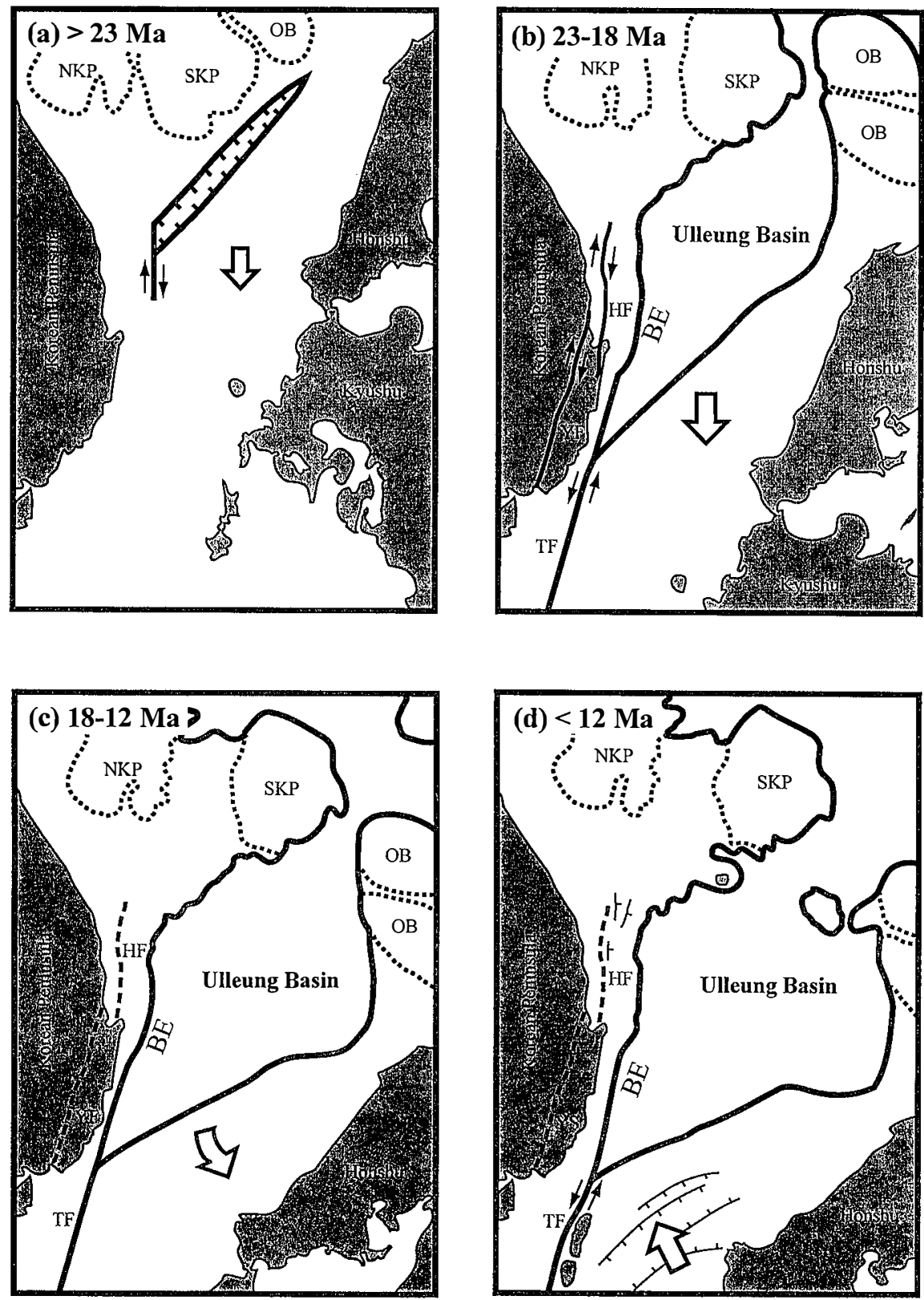

Fig. 2. Evolutionary model of the Ulleung Basin (modified from Yoon and Chough 1995) showing different stages of tectonic development. The thick arrows represent the motion of the continental blocks relative to the Korean peninsula. BE: basement escarpment; HF: Hupo Fault; NKP: North Korea Plateau; OK: Oki Bank; SKP: South Korea Plateau; TF: Tsushima Fault; YF: Yangsan Fault. 


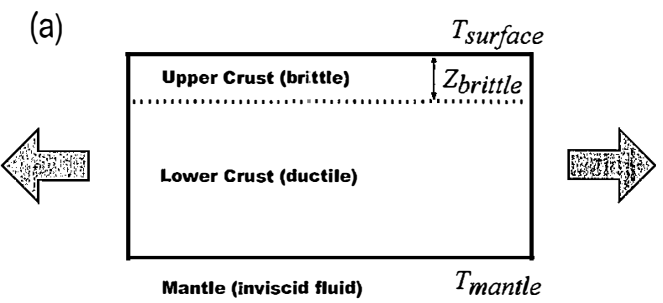

(b)

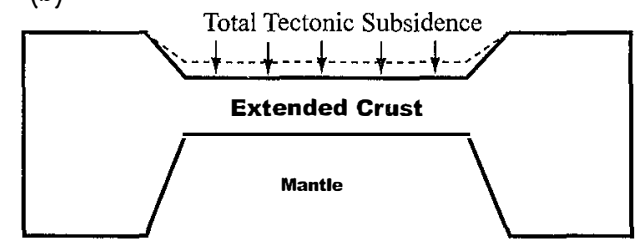

(c) Small $T_{e}$

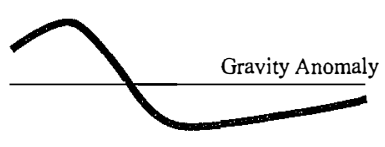

sea surface

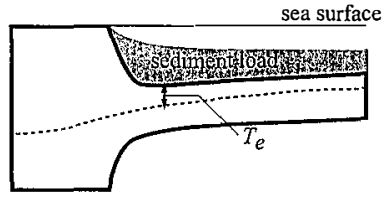

(d) Large $T_{e}$

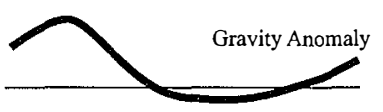

sea surface

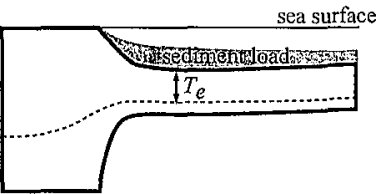

Fig. 3. Schematic diagram of the basin rifting and flexural model used in this study. (a) Prior to rifting the crust comprises of brittle upper and ductile lower crusts. Upon extension, it is the ductile lower crust that is mostly extended. $Z_{\text {brittle }}$ is the onset depth of brittle deformation which is controlled by the strain rate and the temperature of the crust. $\mathrm{T}_{\text {surface }}$ and $\mathrm{T}_{\text {mantle }}$ is temperature of the surface and mantle, respectively. (b) Extension of the crust results in the tectonic subsidence and thermal subsidence from thermal contraction. The two subsidences are referred to as the total tectonic subsidence, whose value depends on the strength factor. The deformation of the crust occurs according to the Airy's isostasy. High heat flow is expected over the extend crust, which gains a finite mechanical strength upon cooling. The crust deforms to sediment loading in elastic manner. (c) and (d) are examples of crustal deflection and the resulting gravity anomaly for crust with small and large elastic thickness $\left(T_{e}\right)$, respectively. 
only a fraction of the total tectonic subsidence, and therefore it will not change the result of our modeling by much.

The first step of our analyses involves removing the flexural subsidence due to sediment load and restoring the crust to its pre-loading configuration. To do this, one has to assume an elastic thickness value for the basin crust. Seismic profile is used to determine the upper boundary of the crust and the sediment load. The lower boundary of the crust is determined by assuming isostasy. The validity of assumed elastic thickness can be tested by computing the gravity anomaly from the resulting crustal structure using the method of Talwani et al. (1959) and comparing it with the observed. The most plausible elastic thickness is chosen by trial and error as one that minimizes the misfit between the observed gravity anomaly and the predicted by forward gravity modeling. For the sake of simplicity, sediment erosion and paleo-sea level changes are ignored in our study.

Flexural subsidence (backstripping) can be calculated using the Euler-Bernoulli beam equation as follows:

$$
\frac{d^{2}}{d x^{2}}\left(D \frac{d^{2} \omega}{d x^{2}}\right)+\left(\rho_{m}-\rho_{w}\right) \omega g=q(x)\left(\rho_{\text {infill }}-\rho_{w}\right) g, \quad D=\frac{E T_{e}^{3}}{12\left(1-\sigma^{2}\right)}
$$

where $D(x)$ is the flexural rigidity as a function of distance $x, \rho_{m}$ density of mantle, $\rho_{\text {infill }}$ average density of sediment layer, $\rho_{w}$ density of water, $g$ gravity acceleration, and $T_{e}$ elastic thickness. $q(x)$ represents the sediment thickness as a function of distance $x$, and $w$ is the displacement from which we determined the deformed configuration. In our study, the sedimentary sequence is divided into upper and lower sedimentary layers. Using the velocitydensity relationship, such as that of Ludwig et al. (1970), we prescribe 2.0 and $2.6 \mathrm{gcm}^{-3}$, respectively, as their density. For the density of mantle, we assumed $3.3 \mathrm{gcm}^{-3} . \sigma$ and $E$ represent the Poisson ratio and Young's modulus of the crustal material, respectively. We used 0.25 and $100 \mathrm{GPa}$ as their values. For calculating the isostatic balance and restoring the crust to syn-rift configuration, we used $2.9 \mathrm{gcm}^{-3}$ as the density of the crystalline crust. The density and elastic moduli that were used are similar to those used in the flexural analyses of other marginal basins (e.g., Watts 2001). The flexure equation was solved using the finite element method. Because the basin has a finite width, the model results depend critically on the boundary conditions at the edge. The mirroring method is used to reduce the edge effect.

\section{RESULTS}

For each profile, we searched for the most plausible elastic thickness by backstripping, restoring the crust to syn-rift configuration, and calculating the misfit between the observed and predicted gravity anomalies over a range of elastic thickness values (Fig. 4). The result for SE profile for different elastic thicknesses is shown in Fig. 4a. For $\mathrm{T}_{\mathrm{e}}=5,8,12$ and $15 \mathrm{~km}$, the root mean squares (rms) misfit between the observed and predicted gravity anomalies is 13.1, $3.1,15.1,24 \mathrm{mGal}$, respectively. Hence the best match occurs at $\mathrm{T}_{\mathrm{e}}=8 \mathrm{~km}$ and the corre- 
sponding crustal structure is shown in Fig. $4 \mathrm{~b}$.

The results for P-1 profile are more or less similar to those of SE profile. Shown in Fig. 4c are four different cases of elastic thickness $\left(\mathrm{T}_{\mathrm{e}}=1,5,18\right.$ and $\left.25 \mathrm{~km}\right)$ for $\mathrm{P}-1$ profile. The rms misfit for these four cases is 7.3, 4.5, 21.2 and $32.7 \mathrm{mGal}$, respectively. The elastic thickness that best matches the observed gravity anomaly is $10 \mathrm{~km}$ for P-1 profile (Fig. 4d). Again, as in profile SE, the model gravity anomaly is lower than the observed over the basin for low elastic thickness, but becomes higher with increasing elastic thickness.

Profile P-2 is located on the SW corner of the Ulleung Basin (Fig. 1). The results of our calculation along profile P-2 differ substantially from those of SE and P-1 (Figs. 4e, f). The model results do not provide a reasonable match with the observed over a range of elastic thicknesses that were considered. For instance, for $\mathrm{T}_{\mathrm{e}}=1,5,9$ and $15 \mathrm{~km}$, the rms misfit between the observed and modeled gravity anomalies is $6.8,12,14$ and $16.8 \mathrm{mGal}$, respectively.

\section{DISCUSSION AND SUMMARY}

In this study, we regarded the Ulleung Basin as extended continental crust on which the sediment is loaded. The three profiles transect not only geographically different parts of the Ulleung Basin but also different types of the margin according to the basin evolution model (Fig. 2). SE and P-2 profiles cross where the margin appears to have undergone N-S extension, whereas in the case of P-1 profile, there may have been strike-slip motion in addition to extension (Fig. 1). Of the three profiles that were examined, two profiles (SE and P-1 profiles) yielded a reasonable match between the observed and modeled gravity anomalies and suggest that the gravity anomaly of the Ulleung Basin can be explained reasonably by a crust having a low elastic thickness of 8-10 km.

The elastic thickness of $8-10 \mathrm{~km}$ that we obtained is substantially lower than that of passive margin such as the Atlantic margin (Watts 1988) but consistent with that of marginal basins that have undergone rapid extension (e.g., Watts and Torné 1992; Weissel and Karner 1989). The fact that old passive margins, such as Atlantic, exhibit high elastic thickness (> 30 $\mathrm{km}$ ), can be explained by their longer cooling history. The Ulleung Basin, on the other hand, is much younger than the Atlantic margin by more than 100 Myr. In fact, the elastic thickness of Ulleung Basin crust is comparable to the same age oceanic crust that has undergone conductive cooling since its formation at mid-ocean ridge. For instance, the average elastic thickness of 20-My-old oceanic crust based on the depth of $450^{\circ} \mathrm{C}$ isotherm is approximately $12 \mathrm{~km}$.

It is important to consider the results of modeling in the context of the tectonic evolution of Ulleung Basin. One of the interesting results of our study is that P-1 profile, which crosses the western margin of the Ulleung Basin where strike-slip movement was the mode of tectonic motion, matches quite well with our extensional model. It will be worthwhile to compare how well the P-1 profile matches a broken plate model where the continental margin and basin is divided by a vertical fault. Unfortunately, this is beyond the scope of the present study. On the other hand, it may not be surprising at all that P-1 profile matches so well. In general pullapart basins will undergo some degree of rotation in the process of becoming wider. If this happens, it means that strike-slip boundary can also be subjected to extension. However, in 

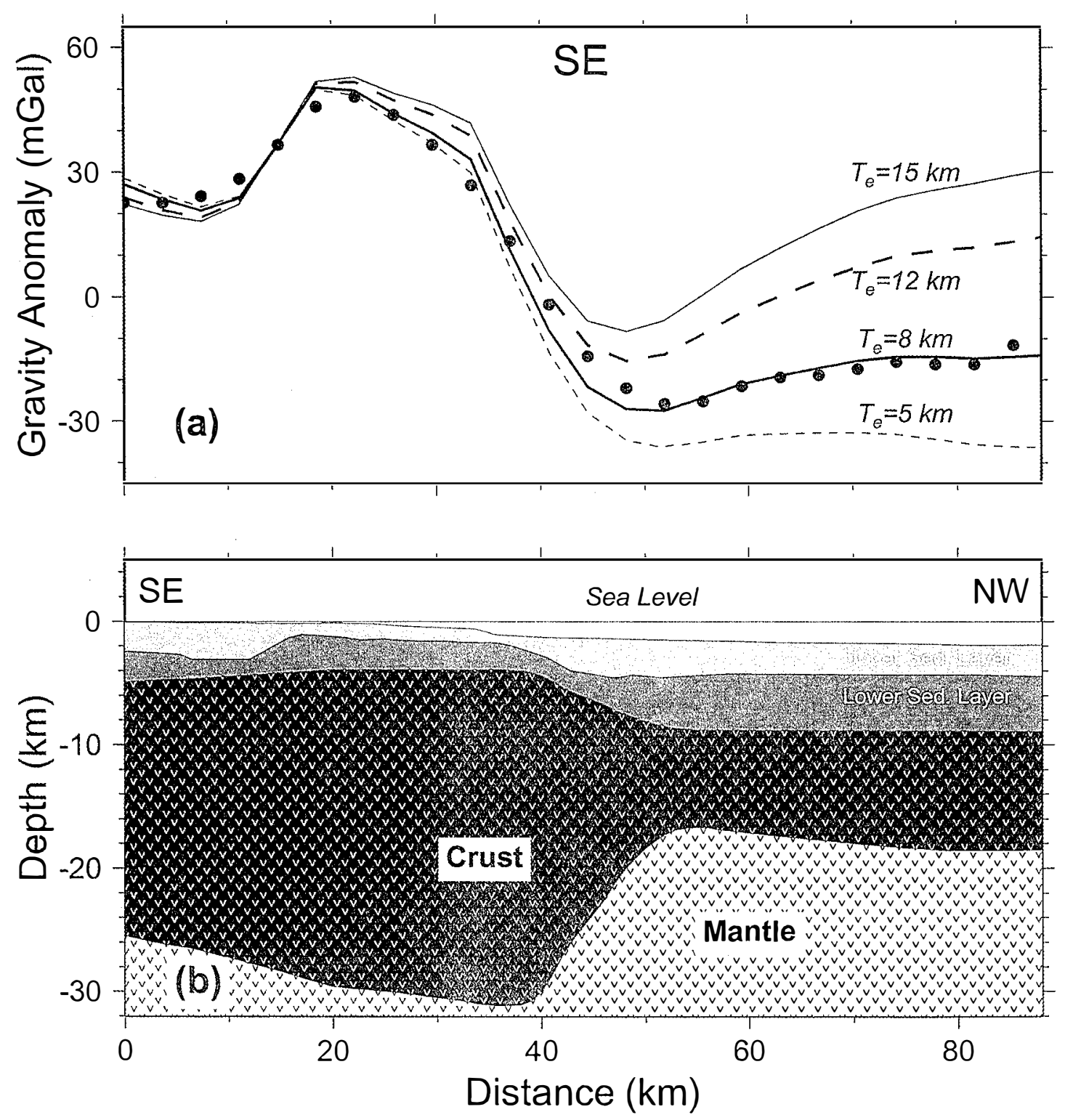

Fig. 4. Comparison between the model and observed (dotted) free-air gravity anomalies for profiles (a) SE (c) P-1 and (e) P-2. Free-air gravity anomalies calculated for different elastic thickness values are shown in different line type. The lower plots ( $b, d$ and $\mathrm{f}$ ) represent the crustal structure that best matches the observed gravity anomaly. For profiles (b) SE and (d) P-1, this corresponds to elastic thickness of 8 and $10 \mathrm{~km}$, respectively. For profile P-2 (f), no particular elastic thickness value appears to match the observed gravity anomaly. 

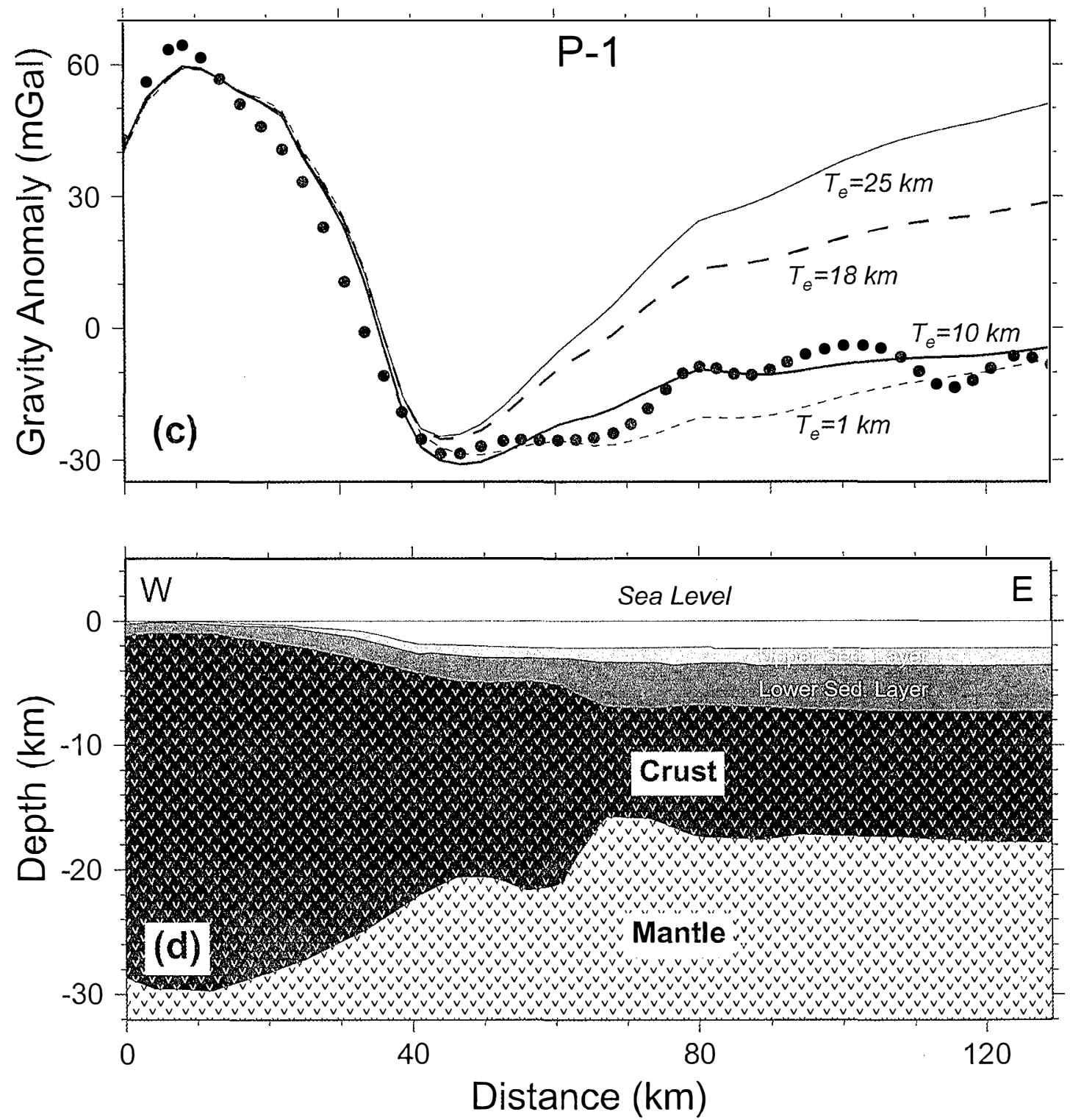

Fig. 4. Continued

this particular case, it is also possible that it experience an extension as a result of rotation of the Japanese Arc in middle Miocene (Fig. 2c). A more detailed study will be needed to resolve this issue.

In the case of P-2 profile, our extensional model fails to match the observed anomaly. There may be a couple of reasons for that. One is that this region around P-2 profile (SW corner of Ulleung Basin) is covered by relatively thick sediment within some areas exceeding $9 \mathrm{~km}$. For our method to work successfully, it is important that the coverage includes the 

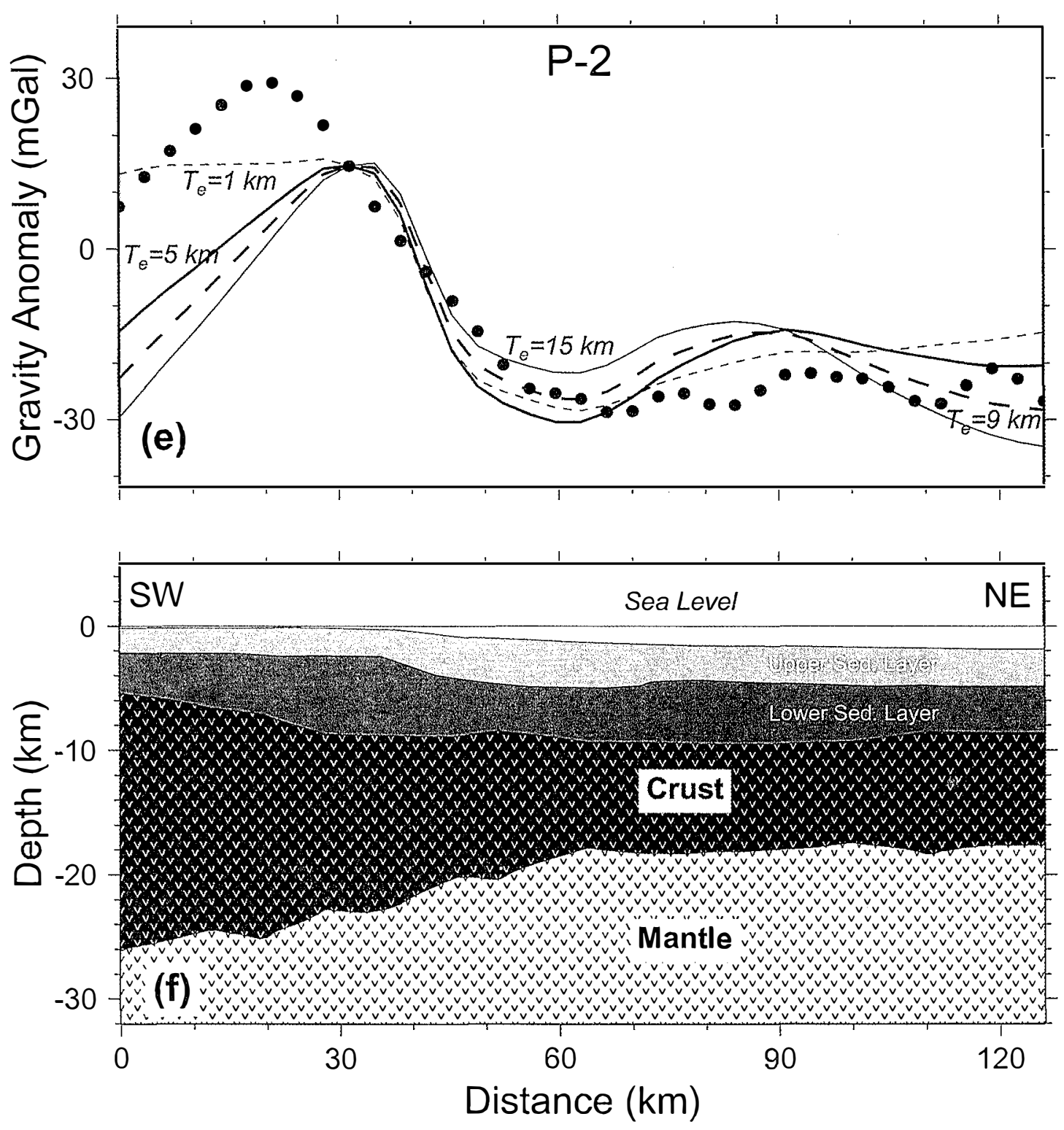

Fig. 4. Continued

margin where there is little or no sediment as well as the basin part with substantial sediment so that one can examine the effect on sediment loading on the extended part of the crust. This was the situation for profiles P-1 and SE. In the case of P-2 profile, however, both the margin and basin are underlain by thick sediment.

Still the gravity mismatch between the observed and modeled for P-2 profile may be too large (> $20 \mathrm{mGal}$ ) to be explained by similarity in crustal structure alone. A more important effect of the mismatch may be that it is caused by compressional stress acting on the SW 
margin as a result of the closure of Ulleung Basin in the last $12 \mathrm{Ma}$ (Fig. 2d). The same compressional stress which caused wide-spread thrust faults within the sedimentary sequence (Chough et al. 1997) may have also caused the underlying crust to buckle. The proximity to Tsushima Fault may be another reason, as the crustal structure along P-2 profile, especially the southern part, could be affected by this fault zone (Fig. 1). If so, the underlying structure may be quite complex, and therefore can not be explained by a simple 2-D extensional model. Unlike the SW margin, there is no evidence of compression in the SE margin of the Ulleung Basin.

The flexural analysis method employed in this study is quite straightforward and robust. However, the method depends on the basic assumptions which we discussed extensively in previous sections. Some of the assumptions, such as uniformity of elastic thickness in the extended crust, need to be investigated further by future studies. In particular, if the opening of the Ulleung Basin occurred over a long time, such assumptions may be contested. However, the current heat flow measurements of the Ulleung Basin (A. Tanaka, personal communications), which exhibit a relatively high average value, appear to be consistent with rapid basin extension. Another important point that needs to be made is that the configuration of our model, in particular the depth to crustal basement, depends very much on quality of seismic profiles. In the case of P-2 profile, the quality of seismic data was rather poor and there were parts of the section where one could not determine the crustal basement, and thus it is possible this may have contributed to the apparent misfit in gravity anomaly. Despite such simplicity and the obvious shortf all that we have little seismic evidence to confirm our deep crustal structure, the fact that the result of our study is quite consistent with the evolutionary model of Ulleung $B$ asin is quite intriguing and is an important conclusion of this paper.

Acknowledgements We would like to thank Han-Joon Kim of KORDI and Takeshi Sato of JAMSTEC for providing the seismic profiles. Comments by Chao-Shing Lee and an anonymous reviewer improved the manuscript. This work was supported by KORDI's Daeyang Program (2000-2002), PE82400, PE85000 and PE85802, and partly by SNU BK21 Program.

\section{REFERENCES}

Alt, J. C., H. Kinoshita, L. B. Stokking, and P. J. Michael, 1996:(Eds.), Proc. ODP, Scientific Results, 148, College Station, TX (Ocean Drilling Program).

Chough, S. K., and E. Barg, 1987: Tectonic history of Ulleung basin margin, East Sea (Sea of Japan), Geology, 15, 45-48.

Chough, S. K., S. H. Yoon, and S. J. Park, 1997: Stratal patterns in the southwestern margin of the Ulleung Basin off southeast Korea: Sequence architecture controlled by back-arc tectonism, Geo-Marine Lett., 17, 207-212.

Chough, S. K., H. J. Lee, and S. H. Yoon, 2000: Marine Geology of Korean Seas, $2^{\text {nd }}$ ed., 328 pp., Elsevier, Amsterdam.

Goetze, C., 1978: The mechanism of creep in olivine, Phil. Trans. R. Soc. Lond., 288, 99-119.

Jolivet, L., and K. Tamaki, 1992: Neogene Kinematics in the Japan Sea region and volcanic activity of the northeast Japan arc, Proc. ODP, Scientific Results, 127/128 (part 2), 
1311-1331, College Station, TX (Ocean Drilling Program).

Karner, G. D., M. S. Steckler, and J. Thorne, 1983: Long-term mechanical properties of the continental lithosphere, Nature, 304, 250-253.

Kim, H. J., S. J. Han, G. H. Lee, and S. Huh, 1998: Seismic study of the Ulleung Basin crust and its implications for the opening of the East Sea (Japan Sea), Mar. Geophys. Res., 20, 219- 237.

Kim, H. J., H. T. Jou, H. M. Cho, H. Bijwaard, T. Sato, J. K. Hong, H. S. Yoo, and C. E. Baag, 2003: Crustal structure of the continental margin of Korea in the East Sea (Japan Sea) from deep seismic sounding data: Evidence for rifting affected by the hotter than normal mantle, Tectonophys., 364, 25-42.

Kim, H. J., C. H. Park, J. K. Hong, H. T. Jou, T. W. Chung, V. Zhigulef, and G. I. Anosov, 1994: A seismic experiment in the Ulleung basin (Tsushima basin), Southwestern Japan Sea (East Sea of Korea), Geophys. Res. Lett., 21, 1975-1978.

Lee, G. H., H. J. Kim, M. C. Suh, and J. K. Hong, 1999: Crustal structure, volcanism, and opening mode of the Ulleung Basin, East Sea (Sea of Japan), Tectonophys., 308, 503525.

Ludwig, W. J., J. E. Nafe, and C. L. Drake, 1970: Seismic refraction, in The Sea, edited by A. E. Maxwell, pp. 53-84, Wiley, new York.

McKenzie, D. P., 1978: Some remarks on the development of sedimentary basins, Earth Planet. Sci. Lett., 40, 25-32.

Sandwell, D. T., and W. H. F. Smith, 1997: Marine gravity anomaly from Geosat and ERS-1 satellite altimetry, J. Geophys. Res., 102, 10039-10054.

Sato, T., 2002: Formation tectonics of the Tsushima basin and the Japan Sea by seismic exploration using bottom seismographs. Ph.D. thesis, Earth and Human Environment Science, Chiba University, Chiba, 62 pp.

Talwani, M., J. L. Worzel, and M. Landisman, 1959: Rapid gravity computations for twodimensional bodies with application to the Mendocino submarine fracture zone, $J$. Geophys. Res., 64, 49-59.

Watts, A. B., 2001: Isostasy and Flexure of the Lithosphere, Cambridge Univ. Press, pp. 458.

Watts, A. B., and J. Stewart, 1998: Gravity anomalies and segmentation of the continental margin offshore West Africa, Earth Planet. Sci. Lett., 156, 239-252.

Watts, A. B., and M. Torné, 1992: Subsidence history, crustal structure, and thermal evolution of the Valencia Trough: Young extensional basin in the Western Mediterranean, $J$. Geophys. Res., 97, 20021-20041.

Weissel, J. W., and G. D. Karner, 1989: Flexural uplift of rift flank due to mechanical unloading of the lithosphere during extension, J. Geophys. Res., 94, 13919-13950.

Yoon, S. H., and S. K. Chough, 1995: Regional strike slip in the eastern continental margin of Korea and its tectonic implications for the evolution of Ulleung Basin, East Sea (Sea of Japan), GSA Bull., 107, 83-97. 